\title{
COMPARISON AND EVALUATION OF PROPOFOL INJECTION PAIN WITH TWO DIFFERENT DOSES OF FENTANYL IN FENTANYL-PROPOFOL MIXTURE
}

\author{
NAGHAM HASHIM, JAAFER H. MAHBUBA \& NOOR ALI \\ ${ }^{1,2}$ Specialist Anesthesia, M.B.Ch.B. /D. A/F.I.C.M.S., Erbil, Iraq \\ ${ }^{3}$ Consultant Anesthesia, M.B.Ch.B./D. A/F.I.C.M.S./C.A.B.A./I.C, M. B. Ch. B., Erbil, Iraq
}

\begin{abstract}
Propofol injection pain is a common problem in anesthesia induction that can be very distressing for patients, so the aim is to compare between two different doses of fentanyl in reducing propofol injection pain. The study was carried out in 90 patients ASA I-II, scheduled to undergo elective surgery over a period of 4 months (from the beginning of June 2016 to the end of September 2016), all of them aged between 19-65 years. Patients were divided into one of the three groups of 30 patients for each group, group C (control) received propofol only, groupM1 received a mixture of fentanyl (100 $\mu \mathrm{g})$ and propofol $(200 \mathrm{mg})$. And groupM2 received a mixture of fentanyl (200 $\mu \mathrm{g})$ and propofol (200 mg). After 10 second of medication, a standard question about the comfort of the injection was asked of the patient. We used a verbal rating scale (VRS) to evaluate propofol injection pain.

The three groups were comparable in respect to the patient's characteristics. The incidence of severe pain on injection of propofol in the control group was 46.7\%, while were $0 \%$ in both of M1 and M2 (P<0.05)

Conclusion: Fentanyl-propofol mixture reduces incidence of propofol injection pain and there was no difference between fentanyl doses. Low dose of fentanyl is cost-effective in mixture techniques to obtain a pain-free environment at the time of propofal induction.
\end{abstract}

KEYWORDS: Pain, Propofol, and Fentanyl

Received: May 16, 2017; Accepted: Jun 05, 2017; Published: Jun 15, 2017; Paper Id.: IJMPSJUN20177

\section{INTRODUCTION}

The propofal is currently one of the most common anesthetic agents used for sedation, induction and maintenance of anesthesia, because of its unique pharmacological properties including its rapid onset time and fast elimination half-life. However, intravenous (I.V.) propofol injections are painful, making the induction of anesthesia uncomfortable for the patient and the anesthesiologist. (1)

Propofol belongs to a group of phenol that can irritate the skin, mucous membrane, and venous intima. Pain at its injection is a common problem in adults, which varies between 30 and $90 \%$. (2)

Pain on injection of propofol can be immediate or delayed. Immediate pain may be caused by direct irritation of afferent nerve ending within the veins, whereas delayed pain probably results from an indirect effect via the kinin cascade. Bradykinin, by producing local vasodilatation and hyper-permeability, may increase the contact between the aqueous phase propofal and the perivascular free nerve ending resulting in pain on injection. This pain has a 10-20 s delayed onset. Despite this discomfort, the incidence of venous sequelae, such as phlebitis, is $<1 \%$. (1) 
Several strategies have been suggested to prevent or reduce pain at the site of propofol administration.(3) Most previous and recent work in this area has been performed on the adjuvant use of hypnotic analgesic anti-inflammatory or local anesthetic drugs, which include adding lignocaine to propofol, cooling or warming propofol, diluting the propofol solution, injection of propofol into a large vein and pretreatment with intravenous injection of lignocaine, ondansetron, metoclopramide, opioids, magnesium or thiopentone with or without tourniquet; granisetron, metoclopramide, magnesium, ketorolac, dexamethasone or thiopentone all have been tried with variable and sometimes conflicting, results. (4-5)

\section{Fentanyl}

Fentanyl is a short-acting pure opioid agonist commonly used for intraoperative and postoperative systemic analgesia. Also, it has some peripherally mediated analgesic action within the clinical dosage range.(7) is a potent, synthetic opioid pain medication with a rapid onset and short duration of action.[HYPERLINK "https://en.wikipedia.org/wiki/Fentanyl"20HYPERLINK "https://en.wikipedia.org/wiki/Fentanyl"] It is a potent agonist at $\mu$-opioid receptors in the brain. Fentanyl is 50 to 100 times more potent than morphine, [HYPERLINK "https://en.wikipedia.org/wiki/Fentanyl"21HYPERLINK "https://en.wikipedia.org/wiki/Fentanyl"] but some fentanyl analogues, which are designed to mimic the pharmacological effects of the original drug, may be as much as 10,000 times more potent than morphine.[HYPERLINK "https://en.wikipedia.org/wiki/Fentanyl"22HYPERLINK "https://en.wikipedia.org/wiki/Fentanyl"]

\section{PATIENTS AND METHODS}

This Prospective clinical trial was conducted in the Erbil Teaching Hospital, and Maternity Teaching Hospitah in Erbil Governorate from June to September 2016.

The study was approved by the scientific council of anesthesia \& Intensive care of the Iraqi board for medical specialization.

The study was carried out on 90 patients, ASA I or II status, that give oral consent to participate in this study. These patients age 19-65 years old scheduled for surgery with general anesthesia for different elective surgery.

\section{Inclusion Criteria}

- $\quad$ ASA physical status I-II according to the ASA's classification system.

- No drug history (opioid, antipsychotic).

- Different elective surgery with general anesthesia.

\section{Exclusion Criteria}

- Patients ASAIII or IV.

- Communication difficulties

- $\quad$ Patient refusal

- Children: because in children the expression of pain is more difficult.

- Psychiatric and neurological disorders 
- History of allergy or contra-indication of the study drugs,

- Use of analgesics or sedative drugs within $24 \mathrm{~h}$ before surgery.

The study was designed in a prospective, randomized, single-blind fashion. Patients were assigned randomly to one of three groups using an Excel generated randomization table. Before anesthesia, it was explained to the patients that they would be receiving i.v. Anesthetics that might cause pain in the forearm. A cannula (20-gauge) was put into a vein on the dorsum of the patient's non-dominant hand of the patients. Before induction, all patients received $5 \mathrm{ml}$ of isotonic saline. All study drugs were prepared preoperatively at room temperature.

- Patient in group C (control) received $5 \mathrm{ml}$ of propofol,

- Patients in groupM1 $5 \mathrm{ml}$ of the mixture of fentanyl and propofol were prepared using 20ml (200 mg) of propofal and $2 \mathrm{ml}(100 \mu \mathrm{g})$ fentanyl and

- Patients in groupM2 $5 \mathrm{ml}$ of the mixture of fentanyl and propofol were prepared using $20 \mathrm{ml}$ (200 mg ) of propofol and $4 \mathrm{ml}(200 \mu \mathrm{g})$ of fentanyl

At an injection speed of $0.5 \mathrm{ml} / \mathrm{s}$. After $10 \mathrm{~s}$ from the medication had been given, a standard question about the comfort of the injection was asked of the patient. We used a verbal rating scale (VRS) to evaluate the severity of pain due to the injection of propofol:

Table 1: Verbal Rating Scale (26)

\begin{tabular}{|c|l|l|}
\hline 0 & No pain & Negative response to questioning \\
\hline I & Mild pain & Pain reported only in response to questioning without any behavioral signs \\
\hline II & Moderate pain & $\begin{array}{l}\text { Pain reported in response to questioning and accompanied by behavioral } \\
\text { signs or pain reported spontaneously without questioning }\end{array}$ \\
\hline III & Severe pain & $\begin{array}{l}\text { Strong vocal response or response accompanied by facial grimacing, arm } \\
\text { withdrawal, or tears }\end{array}$ \\
\hline
\end{tabular}

All patients were able to answer the question; Thereafter induction of anesthesia was continued.

\section{Demographics and Statistical Analysis}

Data will be recorded on a specially designed questionnaire, collected and entered in the computer and then analyzed using appropriate data system which is called Statistical Package for Social Sciences (SPSS) version 22 and the results will be compared between patients with different variables, with a statistical significance level of $<0.05$. The results will be presented as rates, ratio, frequencies, percentages in tables and figures and analyzed using ANOVA and Chi square tests.

\section{RESULTS}

There was no statistically significant associations between different study groups and both of age and weight of the patients,

$\mathrm{P}$-values was not significant and more than 0.05 , with mean $\pm \mathrm{S}$. D age of 11.84 years, and mean $\pm \mathrm{S}$. D weight of $11.11 \mathrm{~kg}$ (Table 2). 
Table 2: Shows the Demographic Data for the Patients

\begin{tabular}{|l|c|c|c|c|c|c|}
\hline Variable & N & Range & Minimum & Maximum & Mean & Std. Deviation \\
\hline Age (Year) & 90 & 46 & 19 & 65 & 35.13 & 11.84 \\
\hline Weight (Kg) & 90 & 49 & 51 & 100 & 71.98 & 11.11 \\
\hline & & & & & & \\
\hline
\end{tabular}

Ninety patients enrolled the study, 28 of them were male and 62 were female (figure4).

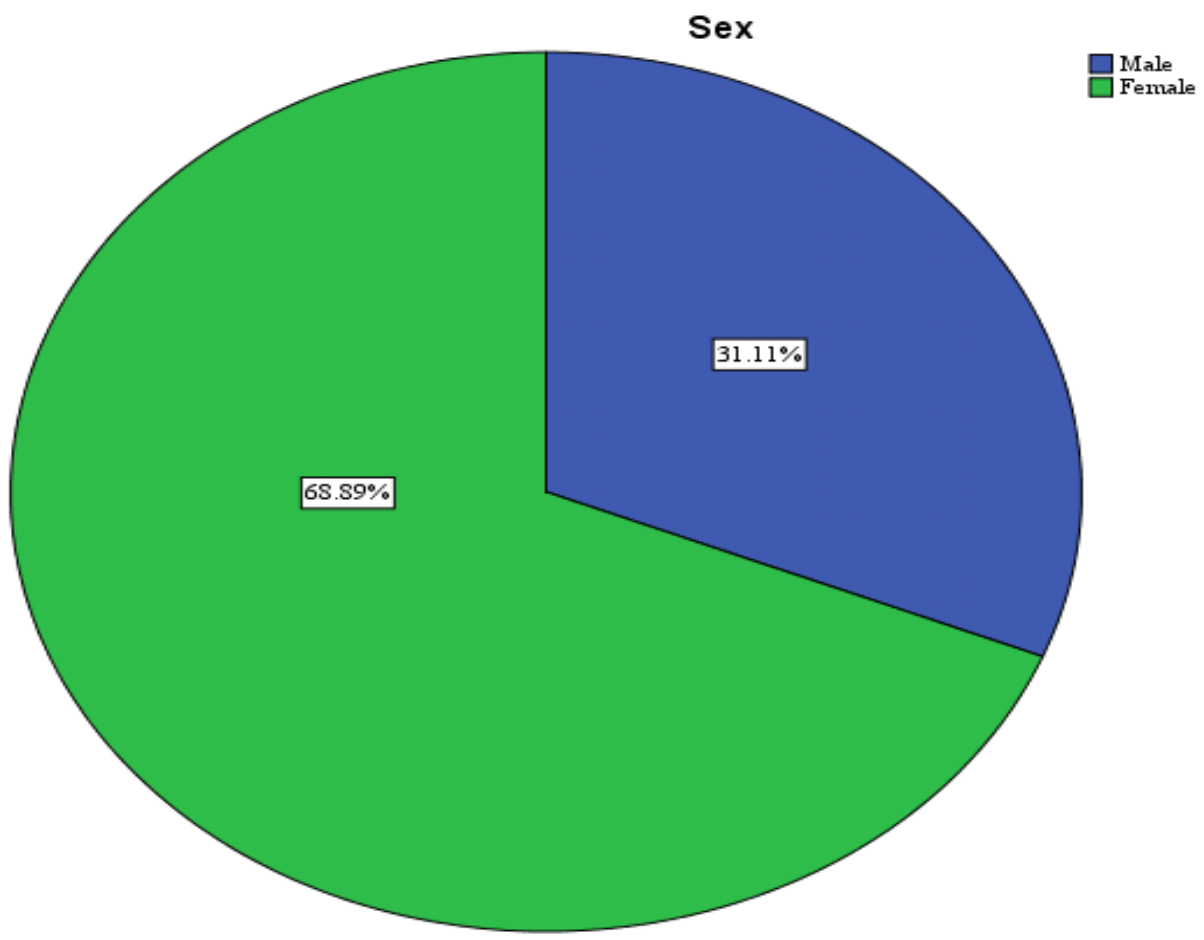

Figure 4: Gender Distribution

In overall, the incidence of no pain was $13.3 \%$ (4/30) in the control group while was 40\% (12/30) in M1 group and 46.7\% (14/30) in M2 group. The overall incidence of severe pain was 46.7\% (14/30) in the control group while was $0 \%$ (no patient suffered from severe pain) in both M1 and M2 group. table3

Table 3: Association between Study Groups and Pain Score

\begin{tabular}{|c|c|c|c|c|c|}
\hline \multirow{2}{*}{$\begin{array}{l}\text { Study } \\
\text { Group }\end{array}$} & \multicolumn{4}{|c|}{ Pain Score } & \multirow{2}{*}{ Total } \\
\hline & No Pain & Mild Pain & Moderate Pain & Severe Pain & \\
\hline \multirow{2}{*}{ Control } & 4 & 4 & 8 & 14 & 30 \\
\hline & $13.3 \%$ & $13.3 \%$ & $26.7 \%$ & $46.7 \%$ & $100 \%$ \\
\hline \multirow{2}{*}{ M 1} & 12 & 12 & 6 & 0 & 30 \\
\hline & $40.0 \%$ & $40 \%$ & $20 \%$ & $0 \%$ & $100 \%$ \\
\hline \multirow{2}{*}{ M 2} & 14 & 10 & 6 & 0 & 30 \\
\hline & $46.7 \%$ & $33.3 \%$ & $20 \%$ & $0 \%$ & $100 \%$ \\
\hline \multirow{2}{*}{ Total } & 30 & 26 & 20 & 14 & 90 \\
\hline & $33.3 \%$ & $28.9 \%$ & $22.2 \%$ & $15.6 \%$ & $100 \%$ \\
\hline
\end{tabular}




\section{Incidence of No Pain}

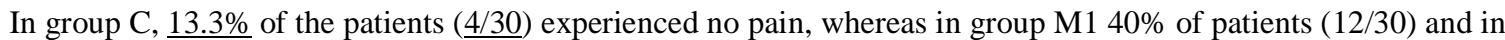
group M2 46.7\% (14/30) of patients experienced no pain. In both groups M1 and M2, the incidence of no pain was significantly higher than in the control group $\left(\mathrm{P}_{-}\right.$value $\left.<0.05\right)$. No difference was found between groups M1 and M2with respect to no pain (P_value: 0.573) (table 5).

Table 5: Incidence of No Pain in M1 and Control Group

\begin{tabular}{|l|l|}
\hline & Frequency \\
\hline Control & $4 / 30(13.3 \%)$ \\
\hline M1 & $12 / 30(40 \%)$ \\
\hline P_ value 0.026 \\
\hline
\end{tabular}

Table 5: Incidence of No Pain in M2 and Control Group

\begin{tabular}{|l|l|}
\hline & Frequency \\
\hline Control & $4 / 30(13.3 \%)$ \\
\hline M2 & $14 / 30(46.7 \%)$ \\
\hline P_value: 0.006 \\
\hline
\end{tabular}

Table 5: Incidence of No Pain in M1 and M2 Group.

\begin{tabular}{|l|l|}
\hline & Frequency \\
\hline M1 & $\mathbf{1 2 / 3 0}(\mathbf{4 0 \%})$ \\
\hline M2 & $\mathbf{1 4 / 3 0}(\mathbf{4 6 . 7 \%})$ \\
\hline P_value: 0.573 \\
\hline
\end{tabular}

\section{Incidence of Mild Pain}

In group C, $\underline{13.3 \%}$ of the patients (4/30) experienced mild pain, whereas in group M1 $40 \%$ of patients (12/30) and in group M2 33.3\% of patients (10/30) experienced of mild pain. In both groups M1 and M2, the incidence of mild pain was significantly higher than in the control group ( $\mathrm{P}_{-}$value $\left.<0.05\right)$. No difference was found between groups M1 and M2with respect to mild pain (P_value 0.564) (Table 6).

Table 6: Number of Patients With Mild Pain in M1 and Control Group

\begin{tabular}{|l|l|}
\hline & Frequency \\
\hline Control & $4 / 30(13.3 \%)$ \\
\hline M1 & $12 / 30(40 \%)$ \\
\hline P_value & 0.023 \\
\hline
\end{tabular}

Table 6: Number of Patients With Mild Pain in M2 and Control Group

\begin{tabular}{|l|l|}
\hline & \multicolumn{1}{|c|}{ Frequency } \\
\hline Control & $4 / 30(13.3 \%)$ \\
\hline M2 & $10 / 30(33.3 \%)$ \\
\hline$P_{\text {_ value }} 0.08$ \\
\hline
\end{tabular}

Table 6: Number of Patients With Mild Pain in M1 and M2 Group

\begin{tabular}{|l|l|}
\hline & \multicolumn{1}{|c|}{ Frequency } \\
\hline M1 & $\mathbf{1 2 / 3 0}(\mathbf{4 0 \%})$ \\
\hline M2 & $\mathbf{1 0 / 3 0}(\mathbf{3 3 . 3 \%})$ \\
\hline P_value: 0.564 \\
\hline
\end{tabular}


Incidence of Moderate Pain

There was no difference in the incidence of moderate pain between the groups M1 and M2 (20\%; 6/30), which was lower than in group C $(26.7 \%$; $8 / 30)$ but statistically not significant (P_value: 0.564$)$ (Table 7).

Table 7: Number of Patients With Moderate Pain in M1 and Control Group

\begin{tabular}{|l|l|}
\hline & \multicolumn{1}{|c|}{ Frequency } \\
\hline Control & $8 / 30(26.7 \%)$ \\
\hline M1 & $6 / 30(20 \%)$ \\
\hline P_value 0.542 \\
\hline
\end{tabular}

Table 7: Number of Patients With Moderate Pain in M2 and Control Group

\begin{tabular}{|l|l|}
\hline & \multicolumn{1}{|c|}{ Frequency } \\
\hline Control & $8 / 30(26.7 \%)$ \\
\hline $\mathrm{M} 2$ & $6 / 30(20 \%)$ \\
\hline $\mathrm{P}$ _ value & 0.542 \\
\hline
\end{tabular}

Table 7: Number of Patients With Moderate Pain in M1 and M2 Group

\begin{tabular}{|l|l|}
\hline & \multicolumn{1}{|c|}{ Frequency } \\
\hline M1 & $6 / 30(20 \%)$ \\
\hline M2 & $6 / 30(20 \%)$ \\
\hline P_value: 1 \\
\hline
\end{tabular}

Incidence of Sever Pain

In group C, $46.7 \%$ of the patients (14/30) experienced severe pain, whereas nopatient did in groups M1 and M2 (statistically was significant (P_value: 0.00) (Table8).

Table 8: Number of Patients With Sever Pain in M1 and Control Group

\begin{tabular}{|l|l|}
\hline & \multicolumn{1}{|c|}{ Frequency } \\
\hline Control & $14 / 30(46.7 \%)$ \\
\hline M1 & $0 / 30$ \\
\hline$P_{\text {_ value }} 0.000$ \\
\hline
\end{tabular}

Table 8: Number of Patients With Sever Pain in M2 and Control Group

\begin{tabular}{|l|l|}
\hline & \multicolumn{1}{|c|}{ Frequency } \\
\hline Control & $14 / 30(46.7 \%)$ \\
\hline $\mathrm{M} 2$ & $0 / 30$ \\
\hline $\mathrm{P}$ _ value 0.000 \\
\hline
\end{tabular}

Table 8: Number of Patients With Sever Pain in M1 and M2 Group

\begin{tabular}{|l|l|}
\hline & Frequency \\
\hline M1 & $0 / 30(0 \%)$ \\
\hline M2 & $0 / 30(0 \%)$ \\
\hline P_value: 1 \\
\hline
\end{tabular}

\section{DISCUSSIONS}

Propofol is currently one of the most common anesthetic agents used for sedation, induction, and maintenance of anesthesia, because of its unique pharmacological properties including its rapid onset time and short duration, injection pain which is a most common side effect.(1) 
Many studies had been done to attenuate the pain during propofol injection.

In this study, we compared the efficacy of low dose of fentanyl to attenuate the propofol pain.

In our study the overall incidence of no pain during injection of propofol in the control group was $13.3 \%$ compared with $40 \%$ in M1, with $46.7 \%$ in M2 group.

It is found that there was a significant difference in the incidence of no pain in the control group in comparison to both the groups who received propofol-fentanyl mixture $(\mathrm{P}<0.05)$.

In this study the severity of pain is decreased with fentanyl-propofol mixture compared with the control group, and there was no difference between fentanyl two doses, there was no patient (0\%) suffered from sever pain in both groups who received fentanyl-propofol mixture while there were 14 patients $(46.7 \%)$ suffered from sever pain in the control group (P_value: 0.000).

In this study, we compare between control group and two groups who received fentanyl-propofol mixture with two different doses of fentanyl, our results shows significant decreased in propofol injection pain in both groups who received mixed compared to the control group and there was no difference between doses of fentanyl in reducing of propofol injection pain, so, low dose of fentanyl is better to reduce costs and side effect.

Nurcan Kizilcik, et al. (27) reported that fentanyl mixed with propofol reduced injection pain significantly compared with the control and fentanyl pretreatment groups which goes with our study and in addition, our study shows no difference between the two doses of fentanyl when mixed with propofol.

Eriksson et al.(28) reported that decreasing the $\mathrm{pH}$ of propofol resulted in a lower concentration of propofol in the aqueous phase, which goes with our study.

Helmer et al. (29) reported a significant decreasing in the incidence of propofol injection pain, from 40 to $16 \%$. In our study, the incidence of severe pain was $46.7 \%$ in the control group and $0 \%$ in both groups who received $2 \mathrm{ml}$ and $4 \mathrm{ml}$ of fentanyl in fentanyl- propofol mixture.

Stewart, et al. (30) shows that propofol and fentanyl were compatible when mixed, which goes with our study that showed, no precipitation was seen in the syringe.

In conclusion, fentanyl mixed with propofol reduced propofol injection pain significantly compared with the control groups and there was no difference between fentanyl doses.

\section{There are other Methods of Decreasing the Pain of Propofol Injection}

- Ondansetron pretreatment to alleviate pain on propofol injection [31].

- Ephedrine reduces the pain from propofol injection (32).

- $\quad$ Small- dose ketamine reduces the pain of propofol injection (33).

- Effect of prior administration of cold saline on pain during propofol

- Injection [34]. 


\section{CONCLUSIONS}

Our study showed fentanyl-propofol mixture reduces the incidence of the propofol injection pain and there was no difference between fentanyl doses. There were no patients with sever pain in the two groups who received fentanylpropofol mixture.

\section{RECOMMENDATIONS}

We recommend that patients receiving fentanyl-propofol mixture for decreasing propofol injection pain is better to receive low-dose of fentanyl which is cost effective and more comfortable to the patient. More studies are to be done on the effect of low dose of fentanyl in fentanyl-propofol mixture.

\section{REFERENCES}

1. Ambesh SP, Dubey PK, Sinha PK. Ondansetron pretreatment to alleviate pain on propofol injection: a randomized, controlled, double blinded study. Anaesth Analg 1999;89:197-9.

2. Mangar D, Holak EJ. Tourniquet at $50 \mathrm{~mm} \mathrm{Hg}$ followed by intravenous lidocaine diminishes hand pain associated with propofol injection. Anaesth Analg 1992;74:250-2.

3. Marik PE. Propofol: therapeutic indication and side-effect. Curr Pharm Des 2004; 10: 3639-49.

4. McCrirrick A, Hunter S. Pain on injection of propofol: the effect of injectate temperature. Anesthesia 1990; 45: 443-4.

5. Stokes DN, Robson N, Hutton P. Effect of diluting propofol on the incidence of pain on injection and venous sequelae. Br $J$ Anaesth 1989; 62: 202-3.

6. James MK, Feldman PL, Schuster SV, Bilotta JM, Brackeen MF, Leighton HJ. Opioid receptor activity of G187087B, a novel ultra-short acting analgesic in isolated tissues. J Pharmacol Exp Ther 1991; 259: 712-8.

7. Mayes S, Ferrone M. Fentanyl HCl patient-controlled iontophoretic transdermal system for the management of acute postoperative pain. Ann Pharmacother. 2006 Dec; 40 (12): 2178-86. PMID: 17164395.

8. Alan Aitkenhead Graham smith, David J Rowbotham, TEXTBOOK OF Anaesthesia, FIFTH EDITHION, ELSEVIER, 2007.

9. Jump up ^Iwersen-Bergmann S, Rösner P, Kühnau HC, Junge M, Schmoldt A (2001). "Death after excessive propofol abuse". International Journal of Legal Medicine 114 (4-5): 248-51. doi:10.1007/s004149900129. PMID 11355404.

10. Nakane M, Iwama H. A potential mechanism of propofol-induced pain on injection based on studies using nafamostate mesilate. Br J Anaesth1999;83: 397-404.

11. Jump up ^ Death Row Improvises, Lacking Lethal Mix, By RICK LYMAN, New York Times, 18 August 2013.

12. Jump up ^ Riezzo I, Centini F, Neri M, Rossi G, Spanoudaki E,Turillazzi E, Fineschi V (2009). "Brugada-like EKG pattern and myocardialeffects in a chronic propofol abuser". Clin Toxicol (Phila) 47 (4): 358-63.doi:10.1080/15563650902887842. PMID 19514884.

13. Jump up ^ Ryder SD, Beckingham IJ (2001). "ABC of diseases of liver, pancreas, and biliary system. Other causes of parenchymal liver disease". BMJ322 (7281): 290-92. doi:10.1136/bmj.322.7281.290. PMC1119531. PMID 11157536.

14. Clinical Anesthesiology a LANGE medical book fifth edition G. Edward Morgan, Jr, MD, Maged S. Mikhail, MD. Page 185186. 
15. Stoelting, Robert K., author. [Handbook of pharmacology \& physiology in anesthetic practice] Stoelting's handbook of pharmacology and physiology in anesthetic practice / Robert K. Stoelting, Steven Shafer, James P. Rathmell, Pamela Flood. - Third edition.

16. Jump up to: a b Miner, JR; Burton, JH (Aug 2007). "Clinical practice advisory: Emergency department procedural sedation with propofol". Annals of Emergency Medicine 50 (2): 182-7. doi:10.1016/j.annemergmed.2006.12.017.

17. Jump up ^Belluck, Pam (6 August 2009). "With High-Profile Death, Focus on High-Risk Drug". New York Times. Retrieved 7 August 2009.

18. Jump up ^ "New York Drug Threat Assessment". National DrugIntelligence Center. November 2002.

19. Nakane M, lwama H. A potential mechanism of propofol-inducedpain on injection based on studies using nafamostate mesilate. Br J Anaesth 1999;83:397-404.

20. Jump up^ "WCPI Focus on Pain Series: The Three Faces of Fentanyl". Aspi.wisc.edu. Retrieved2010-07-28. [permanent dead link]

21. Jump up^ "DrugFacts: Fentanyl". National Institute on Drug Abuse, US National Institutes of Health. June 2016. Retrieved 19 March 2017.

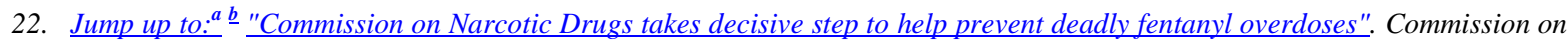
Narcotic Drugs, United Nations Office on Drugs and Crime. 16 March 2017. Retrieved 19 March 2017

23. Jump up^Smydo, J. (1979). "Delayed respiratory depression with fentanyl". Anesth Prog. 26(2): 478. $\underline{P M C} \bigodot_{2515983} \underline{P M I D} \underline{295585}$.

24. Jump up^ "Fentanyl Patch Can Be Deadly to Children". FDA Consumer Information on drugs.com site. U.S. FDA(Drugs.com). April 19, 2012. Retrieved July 30, 2013

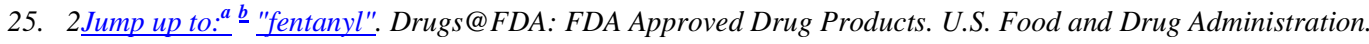

26. 26- Pain Management: Theory and Practice, edited by RK Portenoy \& RM Tanner, copyright 1996 by Oxford University Press, Inc. Used by permission of Oxford University Press.

27. Nurcan Kizilcik, Ferdi Menda, Sevgi Bilgen, Ozgul Keskin, and Ozge Koner. Effects of a fentanyl-propofol mixture on propofol injection pain: a randomized clinical trial Korean J Anesthesiol 2015 December 68(6): 556-560. http://dx.doi.org/10.4097/kjae.2015.68.6.556

28. Eriksson M, Englesson S, Niklasson F, Hartvig P. Effect of lignocaine and pH on propofol induced pain. Br J Anaesth 1997; 78: 502-6.

29. Helmers JH, Kraaijenhagen RJ, Leeuwen LV, Zuurmond WW. Reduction of pain on injection caused by propofol. Can J Anaesth 1990; 37: 267-8.

30. Stewart JT, Warren FW, Maddox FC, Viswanatan K, Fox JL. The stability of remifentanil hydrochloride and propofol mixtures in polypropylene syringes and polyvinylchloride bags at 22 degrees-24 degrees C. Anesth Analg 2000; 90: 1450-1.

31. Ambesh et al., Ondansetron pretreatment to Alleviate pain on propofol Injection, Anesthesia and Analgesia, July 1999, vol 89, issue 1, pp. 197-199.

32. Cheong, Mi A, Ephedrine Reduces the pain from Propofol Injection, Anethesian and Analgesia, November 2002, vol. 95, issue 5, pp. 1293-1296.

33. Koo, seung-Woo MD, Small Dose Ketamine Reduces the pain of Propofol Injection, Anesthesian and Analgesia, December 2006, vol. 103, issue 6, pp. 1444-1447. 
34. P. Barker FCA nase, J. A. Langton FCAnase,Effect of prior administration of Cold Saline on Pain during propofol injection, December 1991, vol 46, issue 12. 